\title{
Perancangan Motion Graphic Sebagai Upaya Pengenalan Profesi Bidang Teknologi Maritim FTK ITS Untuk Siswa SMA
}

\author{
Fakhri Azmi dan Denny Indrayana Setyadi \\ Departemen Desain Produk, Fakultas Arsitektur Desain dan Perencanaan, \\ Institut Teknologi Sepuluh Nopember (ITS) \\ e-mail: azmi.fakhri11@gmail.com, denny@dkv.its.ac.id
}

\begin{abstract}
Abstrak-Indonesia dengan segala potensi kekayaan maritim sebagai negara kepulauan terbesar di dunia, nyatanya masih belum diimbangi dengan kesiapan sumber daya manusia (SDM) untuk memberdayakan sektor tersebut. Perdagangan dunia yang semakin meningkat melalui kapal $(74 \%$ perdagangan dunia melalui laut) menjadi kesempatan dalam berkarir yang terus berkembang untuk profesi sektor teknologi kemaritiman seperti; naval architects, marine engineer, ocean engineer dan sea transportation engineer yang ternyata masih kurang populer dikalangan remaja SMA. Oleh sebab itu dibutuhkan suatu perancangan video motion graphic pengenalan profesi di bidang teknologi maritim dengan target remaja SMA yang akan melanjutkan pendidikan ke jenjang yang lebih spesifik sesuai minat keprofesian. Penelitian menggunakan metode riset studi literatur, observasi terhadap pihak FTK ITS yang memiliki disiplin ilmu di bidang teknologi kemaritiman sebagai referensi konten, interview untuk mengetahui langkah FTK ITS mengenalkan profesi kemaritiman dan penyebaran kuisioner terhadap target perancangan. Teknik motion graphic gaya vektor digunakan sebagai gaya visual. Hasil yang telah tercapai dalam perancangan ini berupa 5 seri video, untuk kemudian dapat didistribusikan dengan media yang bersinergi dengan pihak FTK ITS.
\end{abstract}

Kata Kunci - motion graphic, profesi, teknologi maritim.

\section{PENDAHULUAN}

$\mathrm{S}_{\mathrm{p} \text { the }}^{\mathrm{E}}$ ECARA geografis letak Indonesia yang begitu strategis $\checkmark$ pada jalur pelayaran dapat menjadi potensi tersendiri dalam peningkatan ekonomi dan Indonesia memiliki 4 dari 23 perlintasan laut strategis yang ada di dunia, dimana $74 \%$ perdagangan dunia dibawa oleh kapal [1]. Diperkirakan seperempat dari barang-barang yang ada di dunia melintasi kawasan perairan Indonesia melalui jalur Selat Malaka yang merupakan kawasan aktif lalu-lintas perdagangan laut dengan jumlah mencapai 50 ribu kapal setiap tahun [2]. Hal ini setara dengan sekitar 140 kapal per hari. Menurut Celeste Baine dalam bukunya The Maritime Engineer; Naval Architecture, Marine Engineering dan Ocean Engineering adalah bidang yang tumbuh cepat dan dinamis dengan banyak kesempatan yang meningkat saat orang beralih ke lautan untuk sumber daya seperti makanan, transportasi dan energi. Upaya memajukan industri maritim nasional yang begitu besar tentunya membutuhkan SDM yang mumpuni. Fakultas Teknologi Kelautan ITS Surabaya adalah salah satu fakultas yang mempelajari disiplin ilmu teknologi kemaritiman tersebut. Pemerintah, industri dan akademisi sangat membutuhkan para ahli dan peneliti untuk mengembangkan proses dan sistem baru untuk mengeksplorasi dan melakukan perjalanan laut dengan minimum atau tanpa bahaya sama sekali bagi habitat dan lingkungannya.

Sampai sekarang Indonesia masih berjuang menuju kedaulatan maritim. Ironisnya paradigma pembangunan dan SDM bangsa di Indonesia masih seringkali mengabaikan sektor laut sebagai prioritas utama pembangunan dan lebih memprioritaskan sektor daratan. Data sensus penduduk 2010 menyebutkan, jumlah penduduk Indonesia 237.556.363 orang. Dari jumlah tersebut, hanya 2.313.006 orang yang menggeluti bidang maritim termasuk prajurit TNI AL yang jumlahnya ada 70.000. Menurut Kepala Staf TNI Angkatan Laut, Laksamana TNI Ade Supandi, Jumlah tersebut hanya 1\% dari total penduduk yang bergiat di bidang maritim, berbanding jauh dengan luas lautan 74,26\% dari total luas wilayah Indonesia. Oleh karena itu, agar perekonomian sektor maritim cepat tumbuh, maka kualitas sumber daya manusia bidang maritim harus dapat ditingkatkan sehingga dapat mengolah sumber daya sumber daya alam sektor maritim yang begitu banyak.

Berdasarkan pencarian sederhana penulis, belum terdapat suatu media yang bertujuan untuk menginformasikan profesi di bidang kemaritiman di Indonesia. Suatu media informasi dibutuhkan sebagai upaya untuk mengenalkan peluang karir di bidang industri maritim agar khalayak dapat menyadari pentingnya sektor maritim sebagai suatu pembangunan bangsa dan menjadi aset sumber daya manusia yang lebih berperan aktif untuk pengembangan teknologi maritim Indonesia. Media yang digunakan untuk menggambarkan konten tersebut berupa video Motion graphic yang merupakan gabungan dari potongan elemen - elemen desain/animasi berbasis pada media visual yang menggabungkan bahasa film dengan desain grafis. Pada era digital saat ini, video jenis motion graphic dipilih karena dapat didistribusikan dengan mudah dan mudah menyebar melalui website atau media sosial.

Target audiens remaja khususnya yang menempuh jenjang pendidikan SMA (rentang usia 15-19) yang akan melanjutkan pendidikan ke jenjang yang lebih spesifik sesuai minat keprofesian, dimana remaja pada usia ini telah siap untuk memenuhi syarat bagi pendidikan pasca sekolah lanjutan dengan mengambil mata pelajaran yang diperlukan oleh tipe program dan lembaga yang diinginkan karena telah mampu 
menganalisis kompetensi pribadi untuk pilihan karir. Selain itu, berdasarkan riset sederhana penulis, Remaja SMA (lingkup kota Surabaya) masih belum begitu mengenal profesi yang bergiat di bidang teknologi maritim.

Kementerian Komunikasi dan Informatika RI mencatat pengguna internet di Indonesia tahun 2014 menembus angka 82 juta, dimana $80 \%$ dari jumlah tersebut adalah remaja usia 15-19 tahun yang menjadi target audiens perancangan ini. Perancangan media video dengan konsep "motion graphic" akan lebih mudah dan efektif dikonsumsi target audiens dengan konten yang menarik serta tepat pada target sasaran.

\section{A. Identifikasi Masalah}

1. Paradigma pembangunan dan SDM bangsa di Indonesia yang mengabaikan sektor laut sebagai prioritas utama pembangunan bangsa.

2. Rendahnya popularitas profesi di bidang teknologi maritim ditunjukkan dengan hasil riset penulis serta jumlah SDM yang bergiat dibidang tersebut masih jauh dari harapan.

3. Belum adanya suatu media yang bertujuan untuk menginformasikan profesi di bidang kemaritiman.

\section{B. Rumusan Masalah}

Bagaimana merancang video motion graphic sebagai upaya pengenalan profesi di bidang teknologi maritim Indonesia yang informatif untuk remaja SMA?

\section{Batasan Masalah}

1. Luaran/output yang dihasilkan berupa media video motion graphic yang dapat didistribusikan melalui website atau media sosial serta dapat dikonsumsi melalui perangkat digital seperti smartphone, tablet ataupun laptop.

2. Konten pada perancangan ini berfokus pada informasi pengenalan profesi yang bergiat di bidang teknologi kemaritiman dengan stakeholder Fakultas Teknologi Kelautan ITS Surabaya meliputi cakupan bidang; Naval Architecture; Marine Engineering; Ocean Engineering; Sea Transportation Engineering

3. Sampel penelitian kuisener pada perancangan ini dibatasi hanya pada target audiens remaja SMA yang yang akan meneruskan pendidikan ke jenjang lebih spesifik dengan minat keprofesian berusia 15 hingga 19 tahun.

\section{Tujuan}

Diharapkan dengan adanya perancangan ini dapat memberikan informasi kepada remaja SMA mengenai profesi yang bergiat di bidang teknologi kemaritiman.

\section{METODOLOGI DAN ANALISIS PENELITIAN}

\section{A. Metodologi riset}

\section{1) Studi Literatur}

Metode ini digunakan untuk mendalami subjek penelitian, yaitu penggolongan jenis video motion graphic, serta objek penelitian, yaitu mengenai dunia kemaritiman, melalui kajian literatur ilmiah dan media eksisting. Literatur dan sumber yang digunakan seperti "Animated Storytelling" oleh Liz Blazer serta "The Maritime Engineer" oleh Celeste Baine.

\section{2) Kuisioner}

Metode ini bertujuan untuk mengetahui sejauh mana wawasan target audiens (dalam hal ini adalah remaja SMA) mengetahui profesi sektor kemaritiman Indonesia.

Target Responden : Siswa SMA/SMK di Kota Surabaya

Metode Pelaksanaan : penyebaran kuisioner online

Waktu Pelaksanaan : Oktober 2017

Hasil Kuisioner menunjukkan bahwa profesi sektor kemaritiman masih sangat minim peminat dan tidak sepopuler profesi lainnya, responden masih kurang paham akan eksistensi profesi kemaritiman dan hal tersebut terbukti saat responden diminta untuk menyebutkan profesi yang berkaitan. Meskipun begitu, responden menyadari akan pentingnya sektor kemaritiman bagi pembangunan bangsa.

\section{3) Interview}

Bertujuan untuk mengetahui langkah stakeholder dalam mengenalkan sektor kemaritiman indonesia, mengetahui kondisi terkini mengenai Sumber Daya Manusia (SDM) serta mengajukan storyline yang telah dibuat sebelumnya berdasarkan literatur dan eksisting yang ada. Instruksi yang diberikan oleh narasumber terkait konten dan deskripsi profesi adalah cukup mengikuti konten yang berasal dari website resmi FTK ITS serta media cetak berupa brosur.

\section{4) Observasi}

Metode observasi dilakukan terhadap stakeholder yaitu Fakultas Teknologi Kelautan ITS Surabaya, sebagai salah satu fakultas yang mempelajari disiplin ilmu teknologi kemaritiman. Observasi juga dilakukan sebagai penggalian sumber konten sesuai arahan narasumber interview yaitu mengikuti website dan brosur resmi fakultas.

\section{B. Studi Eksisting}

\section{1) Kenali Pelabuhan Indonesia oleh Monoponik Studio}

Diunggah oleh akun "monoponik studio" melalui situs web youtube (www.youtube.com/watch? $v=e U q 4$ etaZRLk) yang berisi tentang fungsi dari pelabuhan di Indonesia dengan klien PT. Pelabuhan Indonesia II.

2) Video oleh Meritus University Malaysia

Diunggah oleh akun "Meritus University Malaysia" melalui situs web youtube (www.youtube.com/ watch? $v=d C s A d O c T 9 d k$ ) sebagai bentuk ajakan untuk mengetahui prospek pekerjaan yang tersembunyi dalam karir bisnis maritim dengan target audiens para siswa SMA yang akan melanjutkan studi ke jenjang berikutnya.

\section{3) The Blue Denmark}

Sebuah kampanye yang berintegrasi dengan berbagai stakeholder bidang teknologi kemaritiman di Negara Denmark (http://worldcareers.dk/). Target audiens dari kampanye ini adalah remaja berusia antara 17 - 34 dengan pendistribusian media yang sangat beragam, mulai dari website dan berbagai media sosial. 


\section{KONSEP DESAIN}

\section{A. Diagram Penemuan Pesan Utama}

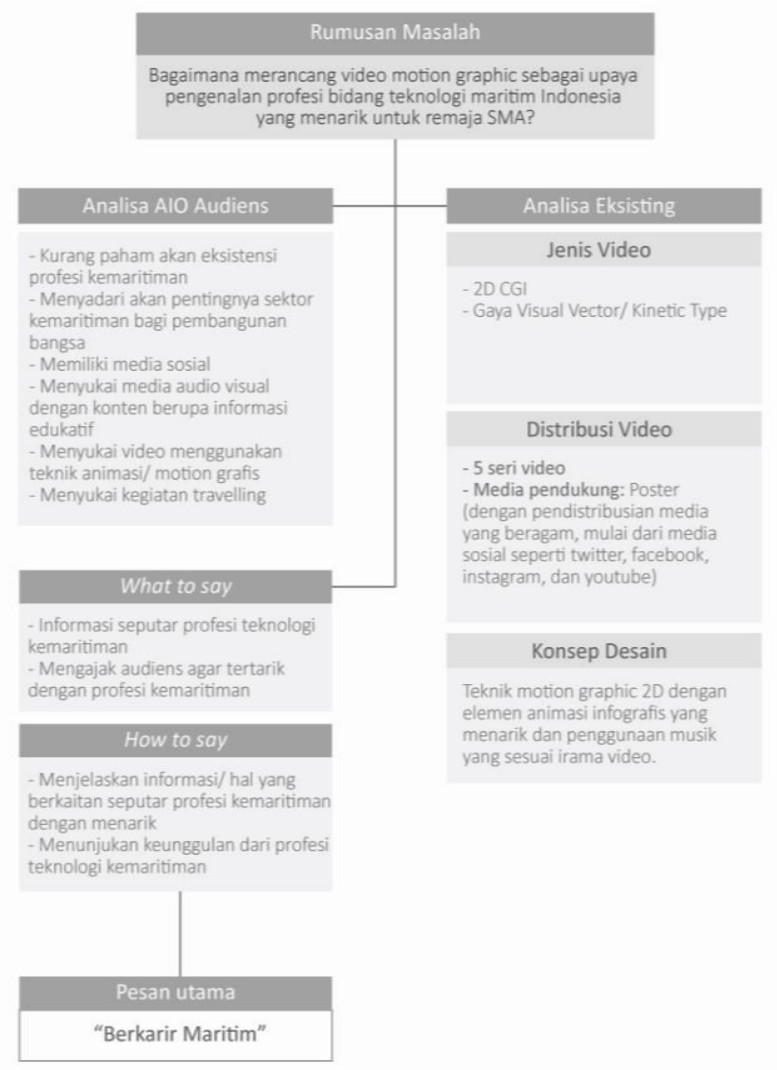

Gambar 1. Diagram Penemuan Pesan Utama.

\section{B. Tahapan Komunikasi}

Output video dari perancangan ini berada pada tahap awal yaitu tahap Introduksi, dimana pada tahap ini fokus penyampaian komunikasinya adalah berupa informasi ringkas untuk mengenalkan profesi teknologi kemaritiman. Sementara tahap lainnya merupakan tahap yang lebih detail mengenai masing-masing profesi teknologi kemaritiman dan juga tahap yang lebih persuasif untuk mengajak audiens kepada pengambilan keputusan.

\section{Pra-Produksi}

\section{1) Teknis Pengerjaan dan Gaya Visual}

Gaya visual yang digunakan adalah 2D flat design (vector) dengan skala warna solid serta kombinasi isometric design untuk menggambarkan objek lebih detail seperti kapal dan platform lainnya yang dibuat dari software pengolah vektor ilustrasi $2 \mathrm{D}$.

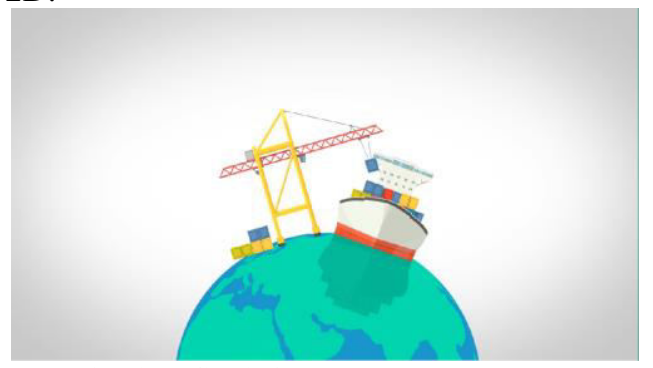

Gambar 2. Gaya visual 2D flat design.

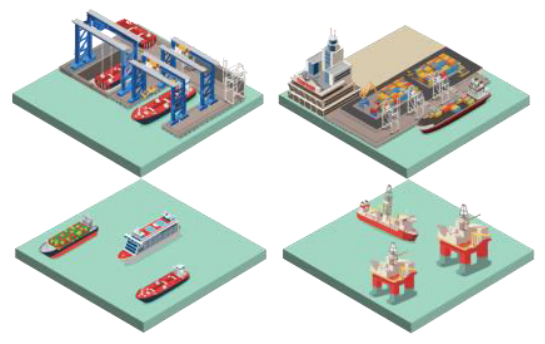

Gambar. 3. Style Isometric design

\section{2) Penggunaan Warna/Tone}

Penggunaan warna dalam motion grafis adalah warna soft, serta bernuansa teduh dengan harmonisasi warna infografis yang memiliki tingkat keterbacaan yang tinggi sehingga informasi mudah terlihat. Menggunakan teori penggunaan warna yang dikemukaan oleh Liz Blazer, membatasi palet warna sehingga tidak terlalu banyak warna dalam sebuah video dan mendukung subjek animasi yang dominasi berwarna maritim yaitu biru.

\section{3) Tipografi}

Pemilihan font/ tipografi berdasarkan eksisting yang menjadi referensi perancangan ini, dan juga berdasarkan tingkat keterbacaan yang tinggi serta memberikan kesan kasual dan fun. Font yang digunakan memiliki perbedaan yang tidak terlalu jauh agar terlihat seirama namun menghindari kebosanan.

\section{ABCDEFGHIJKLMNOPQRSTUVW) ABCDEFGHIJKLMNOPQRSTUVW) 1234567890 !!@\#S\%?q[*^=-1}

Gambar 4. Bebas Neue.

\section{4) Suara}

Setiap seri video perancangan menggunakan suara nondiegitic yaitu suara narasi untuk efek suara yang mendukung motion grafis dimana sumber suara tidak terlihat pada video. Contoh dari tipe suara ini adalah narasi, voice over, atau score musik. Suara non-diegetic memperkaya adegan yang ada pada layar serta menggunakan background music instrumental berirama kasual dan fun.

\section{5) Durasi}

Setiap seri video perancangan memiliki durasi sekitar 1 menit, sehingga konten yang disampaikan terbilang cukup sedikit namun tetap informatif dalam menyampaikan pesan. Durasi yang singkat juga mengikuti aturan beberapa media sosial yang memiliki keterbatasan waktu unggahan video.

6) Aset Visual

Aset visual pada studi ini dapat dilihat pada Gambar 5.

\section{7) Storyline}

Storyline adalah narasi setiap seri video motion graphic berdasarkan focal point yang telah disesuaikan dengan sumber konten perancangan.

a. Seri Umum: Fenomena industri maritim dan 4 profesi teknologi kemaritiman

b. Seri Marine Engineer: Komponen internal kapal

c. Seri Naval Architect: Proses perancangan kapal

d. Seri Ocean Engineer: Proses perancangan bangunan laut 
e. Seri Sea Transportation Engineer: Manajemen bisnis maritim.

8) Storyboard

Storyboard adalah sketsa gambar yang disusun berurutan sesuai naskah cerita yang dibuat. Dengan adanya storyboard akan mempermudah proses pembuatan animasi. Dalam film ini dibuat storyboard yang terdiri dari scene, waktu transisi, dan gambar adegan.

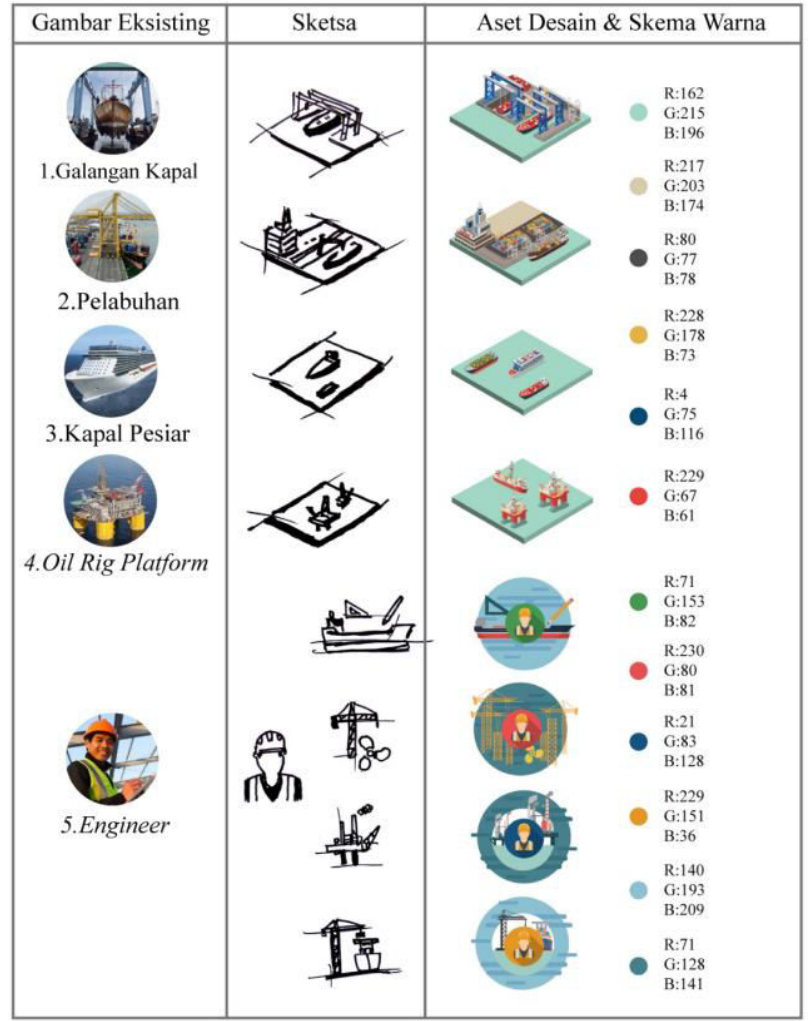

Gambar 5. Aset Visual.
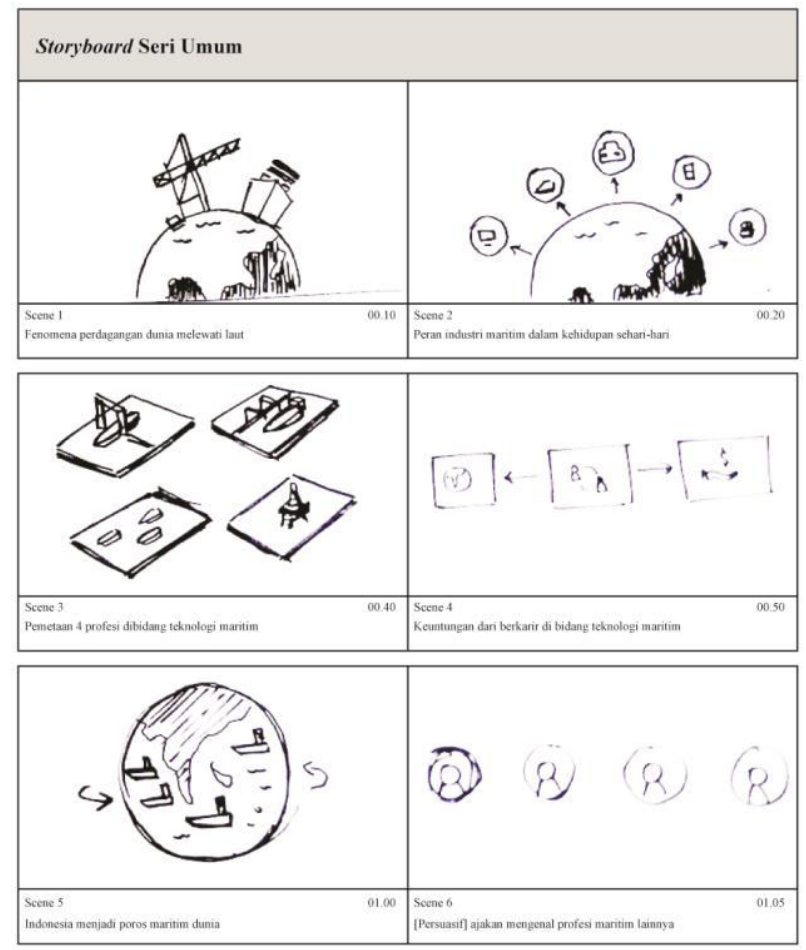

Gambar 6. Storyboard Seri Umum.

\section{9) Storytelling}

Penyampaian cerita dalam video berisi informasi menggunakan Struktur Tiga Babak (Three-Act Structure) yaitu struktur penceritaan linear dengan 3 babak dasar yang dikemukakan oleh Liz Blazer (2016).

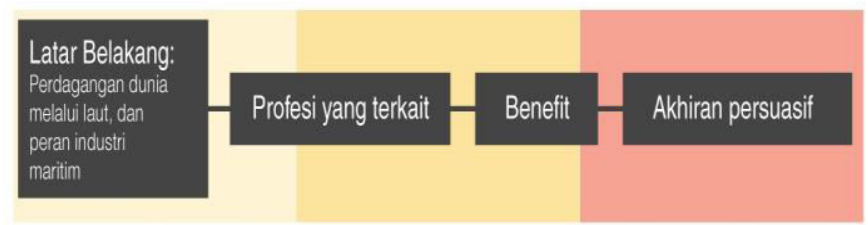

Gambar 7. Storytelling Seri Umum.

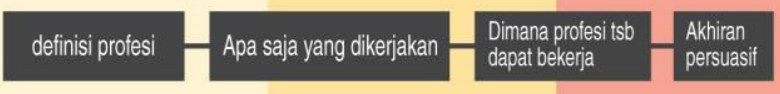

Gambar 8. Storytelling 4 Seri pendukung.

\section{Produksi}

\section{1) Membuat Aset}

Proses pembuatan aset-aset motion graphic dalam perancangan ini menggunakan software pengolah vektor ilustrasi 2D.

\section{2) Animating}

Pada tahap ini aset yang telah diciptakan kemudian disatukan dengan teknik layering atau objek bertumpuk dalam suatu scene. Penggunaan keyframes adalah salah satu teknik yang digunakan untuk menghubungkan aset satu dengan lain untuk mengatur perubahan ataupun perpindahan yang terjadi dalam sebuah video motion graphic. Software digunakan pada tahap ini adalah software pengolah vektor ilustrasi 2D.

\section{E. Pasca-Produksi}

\section{1) Rendering}

Rendering menggunakan software pengolah motion graphic dimana seluruh scene yang digabungkan diberi keyframes dengan output akhir berupa video dengan format H.264 dengan resolusi 1280 x 720 pixels. Hasil akhir dari rendering ini belum termasuk produksi suara narasi dan juga musik pendukung.

\section{2) Compositing}

Tahap akhir / finishing dengan menggabungkan elemen musik, narasi dan video menjadi satu menggunakan software pengolah video.

\section{F. Distribusi Media}

Dari hasil kuesioner, makan dipilih channel Instagram, Youtube dan Facebook sebagai media sosial penyebaran media. Instagram dan Line memiliki perputaran alur informasi yang lebih cepat dibanding Youtube. Pemilihan media ini mempengaruhi ukuran dan durasi dari video. Media sosial yang digunakan menggunakan akun independen "Berkarir Maritim" yang dapat bersinergi dengan pihak stakeholder FTK ITS sehingga penyebaran dapat sesuai dengan segmentasi target. 


\section{DESAIN FINAL}

\section{A. Seri Umum}

Video ini menjelaskan mengenai fenomena industri maritim serta pengenalan awal 4 profesi teknologi kemaritiman yang ditunjukkan dengan 4 sektor profesi.

\section{B. Seri Marine Engineer}

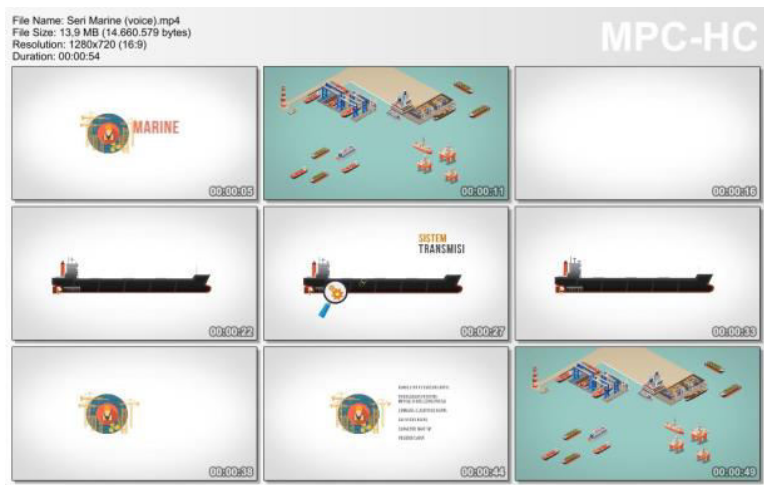

Gambar 9. Screenshot desain final seri Marine Engineer.

Video ini menjelaskan mengenai profesi insinyur yang merancang komponen internal kapal meliputi sistem navigasi, kelistrikan, sistem transmisi, sistem penggerak hingga sistem perpipaan.

\section{Seri Naval Architect}

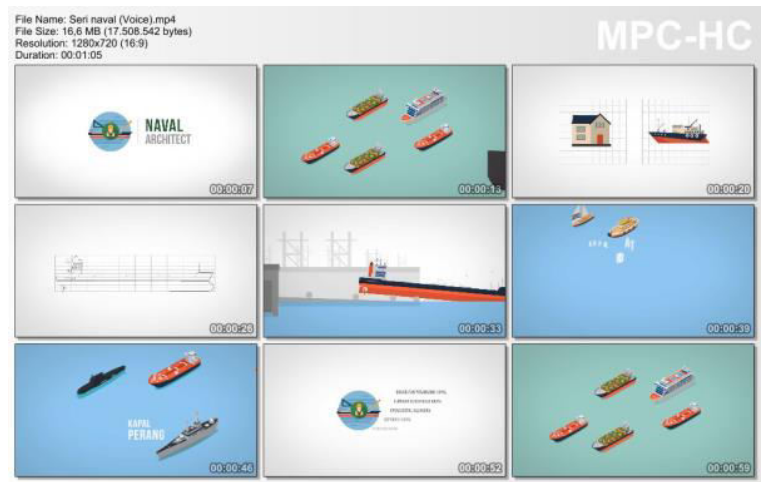

Gambar 10. Screenshot desain final seri Naval Architect.

Video ini menjelaskan mengenai profesi insinyur yang merancang struktur kapal yang dibuat di galangan kapal serta informasi jenis-jenis kapal yang dibuat oleh profesi ini.

\section{Seri Ocean Engineer}

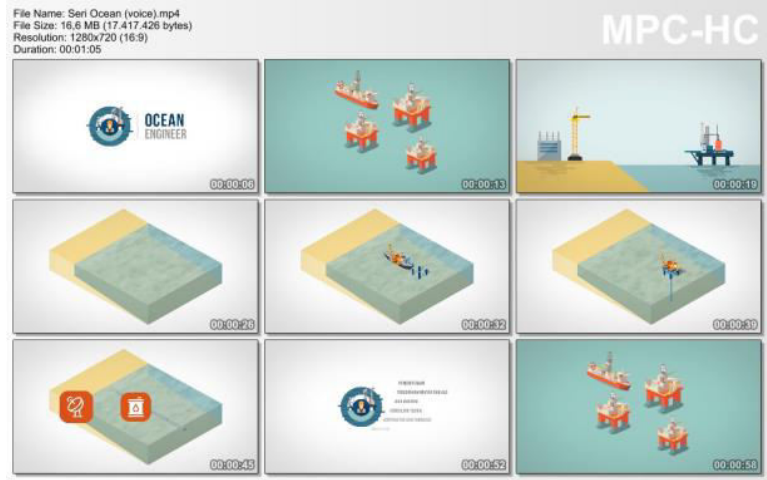

Gambar 11. Screenshot desain final seri Ocean Engineer
Video ini menjelaskan mengenai profesi insinyur yang merancang bangunan lepas pantai serta penjelasan mengenai bagaimana proses bangunan tersebut dibuat dan juga pembuatan sistem perpipaan bawah laut.

\section{E. Seri Sea Transportation Engineer}

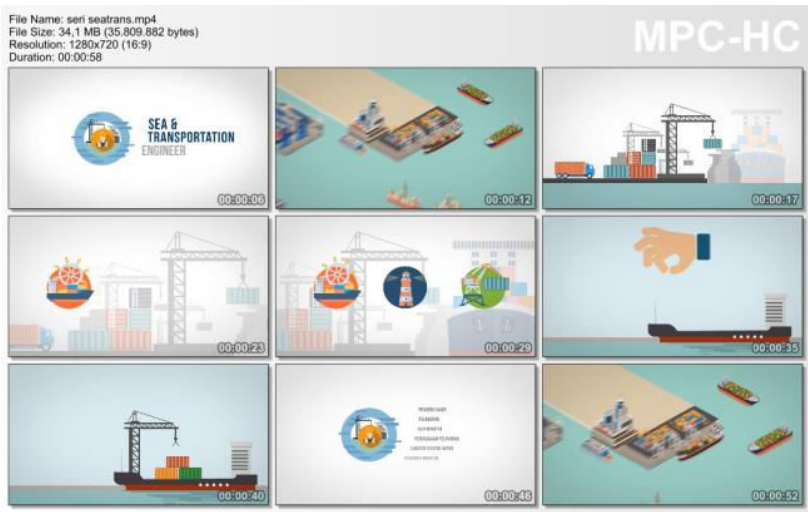

Gambar. 12. Screenshot desain final seri Sea Transportation Engineer

Video ini menjelaskan mengenai profesi insinyur yang merancang pelabuhan agar lebih efisien serta konsep bisnis kemaritiman.

\section{F. Post Test}

Setelah desain selesai dibuat maka selanjutnya penulis melakukan user testing dimana hal ini dilakukan untuk mengetahui apakah desain tersebut dapat menyelesaikan masalah dan menjawab kebutuhan dari objek desain tersebut. User testing berupa post test dilakukan kepada beberapa siswa SMA sebagai target perancangan.

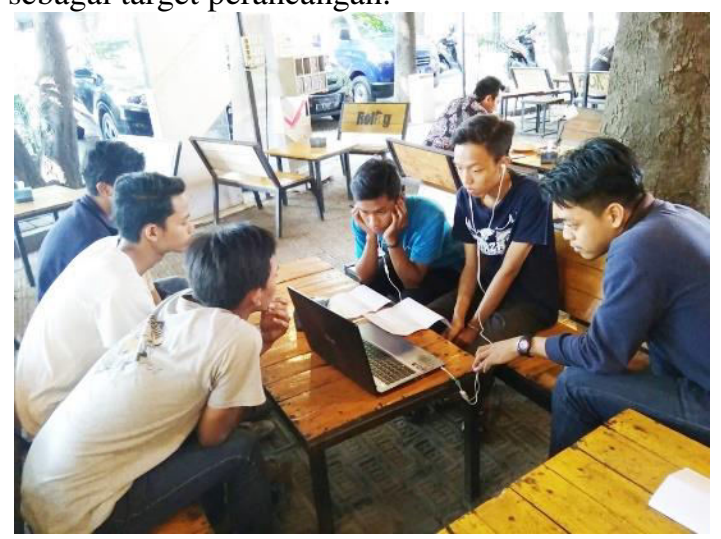

Gambar. 13. Dokumentasi post test kepada target audiens

Berikut adalah variabel pada post test beserta rangkuman hasilnya diantaranya adalah; Sebagian besar target dapat menyebutkan 4 profesi kemaritiman beserta perbedaannya; Dengan menggunakan rata-rata skala antara 1 sampai dengan 5 adalah 3,5 yang artinya mereka cukup tertarik untuk mengetahui lebih lanjut mengenai profesi kemaritiman; Sebagian besar menyebut seri umum dan seri naval architect merupakan bagian paling mudah diingat; Sebagian besar menyebut seri Sea \& Transportation Engineer merupakan bagian yang paling sulit diingat; Sebagian besar target dapat merangkum isi video namun belum $100 \%$ benar; Sebagian besar target mengatakan video menarik dan informatif. 


\section{KESIMPULAN}

\section{A. Kesimpulan}

Berdasarkan hasil analisis karya tulis "Perancangan motion graphic sebagai upaya pengenalan profesi bidang teknologi maritim FTK ITS untuk siswa SMA" dapat diambil sebuah kesimpulan bahwa penyampaian informasi dalam bentuk motion graphic cukup informatif untuk mengenalkan profesi teknologi kemaritiman. Hasil/output yang telah tercapai dalam laporan ini berupa 5 seri video yang telah dilakukan user testing kepada siswa SMA. Luaran tersebut diharapkan dapat dapat menjadi referensi audiens untuk melanjutkan pendidikan ke jenjang selanjutnya.

\section{B. Saran}

Beberapa hal yang menjadi perhatian penulis dalam output dari perancangan ini diantaranya; Aspek persuasif dalam bahasa motion graphic secara visual mengekspresikan emosi target audiens; Aspek persuasif lainnya yang belum maksimal dari segi Audio berupa intonasi narator serta tone musik/ jingle; Tahapan Komunikasi dalam perancangan yang masih dalam tahap introduction/pengenalan dengan fungsi informasi berupa profesi teknologi maritim, belum mencapai tahap isi yang lebih detail tentang masing-masing profesi hingga tahap persuasi yang berfungsi meningkatkan kesadaran target audiens untuk menjadikan profesi tersebut sebagai referensi karir yang diinginkan.

Segala masukan dari pihak stakeholder (FTK ITS) dan juga target audiens saat post test menjadi perhatian penulis untuk pengembangan output perancangan sehingga menjadi lebih baik dikemudian hari.

\section{DAFTAR PUSTAKA}

[1] C. Baine, The Maritime Engineer. Bonamy Publishing, 2011.

[2] N. Quartaro, J. Manicom, J. Bradford, and S. W. Simon, "Maritime Security in Southeast Asia U.S., Japanese, Regional, and Industry Strategies," 2010. 